\title{
Continuous fungal treatment of non-sterile veterinary hospital effluent: pharmaceuticals removal and microbial community assessment
}

\author{
Marina Badia-Fabregat ${ }^{1}$ - Daniel Lucas ${ }^{2}$ - Maria Alcina Pereira ${ }^{3} \cdot$ Madalena Alves $^{3}$. \\ Taina Pennanen ${ }^{4} \cdot$ Hannu Fritze $^{4} \cdot$ Sara Rodríguez-Mozaz $^{2} \cdot$ Damià Barceló $^{2,5}$. \\ Teresa Vicent ${ }^{1} \cdot$ Glòria Caminal $^{6}$
}

Received: 15 September 2015 /Revised: 13 October 2015 / Accepted: 14 October 2015 / Published online: 6 November 2015

(C) Springer-Verlag Berlin Heidelberg 2015

\begin{abstract}
Source point treatment of effluents with a high load of pharmaceutical active compounds (PhACs), such as hospital wastewater, is a matter of discussion among the scientific community. Fungal treatments have been reported to be successful in degrading this type of pollutants and, therefore, the white-rot fungus Trametes versicolor was applied for the removal of PhACs from veterinary hospital wastewater. Sixty-six percent removal was achieved in a non-sterile batch bioreactor inoculated with $T$. versicolor pellets. On the other hand, the study of microbial communities by means of DGGE and
\end{abstract}

Marina Badia-Fabregat and Daniel Lucas contributed equally to this work.

Electronic supplementary material The online version of this article (doi:10.1007/s00253-015-7105-0) contains supplementary material, which is available to authorized users.

Glòria Caminal

gcsqbp@iqac.csic.es

1 Departament d'Enginyeria Química, Universitat Autònoma de Barcelona (UAB), 08193 Bellaterra, Spain

2 Catalan Institute for Water Research (ICRA), H2O Building, Scientific and Technological Park of the University of Girona, 101-E-17003 Girona, Spain

3 CEB-Centre of Biological Engineering, University of Minho, Campus de Gualtar, 4710-057 Braga, Portugal

4 Natural Resources Institute Finland (Luke), Jokiniemenkuja 1, FI-01301 Vantaa, Finland

5 Water and Soil Quality Research Group, Department of Environmental Chemistry (IDAEA-CSIC), Jordi Girona 18-26, 08034 Barcelona, Spain

6 Institut de Química Avançada de Catalunya (IQAC) CSIC, Jordi Girona 18-26, 08034 Barcelona, Spain phylogenetic analyses led us to identify some microbial interactions and helped us moving to a continuous process. PhAC removal efficiency achieved in the fungal treatment operated in non-sterile continuous mode was $44 \%$ after adjusting the $\mathrm{C} / \mathrm{N}$ ratio with respect to the previously calculated one for sterile treatments. Fungal and bacterial communities in the continuous bioreactors were monitored as well.

Keywords Veterinary hospital wastewater · Continuous treatment $\cdot$ Pharmaceutically active compounds $\cdot$ White-rot fungi

\section{Introduction}

Pharmaceutically active compounds ( $\mathrm{PhACs}$ ) are a group of organic micropollutants with raising concern among the scientific community due to their low biodegradability in activated sludge wastewater treatment (Joss et al. 2006; Verlicchi et al. 2012), their presence in surface waters, groundwater, and even tap water (Gros et al. 2012; Jurado et al. 2012), and their associated risks (Verlicchi et al. 2012). Joss et al. (2006) calculated that wastewater dilution, and, hence, dilution of PhAC concentration is detrimental for their biological removal by activated sludge since pseudo first order kinetics were observed for the biological degradation of PhACs. Therefore, treatment at source point (i.e., hospital effluents) could help increase removal of PhACs, taking into account that hospital wastewaters are considered to significantly contribute to $\mathrm{PhAC}$ load entering the wastewater treatment plants (WWTPs) (Santos et al. 2013). Some pieces of work dealing with hospital wastewater treatment can be found in the 
literature (Kovalova et al. 2012; Verlicchi et al. 2010). However, there is no data about the presence of PhACs in wastewaters from veterinary hospitals.

Among all biological treatments, which are more costeffective than physical-chemical ones, the use of white-rot fungi (WRF) has been extensively studied due to its ability to degrade a wide range of organic micropollutants more efficiently than conventional biological treatments. Some studies applying WRF for the degradation of dyes, polycyclic aromatic hydrocarbons (PAHs), pesticides and, most recently, a high variety of PhACs can be found in the literature (Asgher et al. 2008; Harms et al. 2011). However, most of them are performed at lab scale, and there are still few studies scaling up the process set-up from Erlenmeyer to bioreactor scale and even less working under non-sterile conditions. Some of them have dealt with synthetic wastewater (Libra et al. 2003; Nguyen et al. 2013) and fewer with real wastewater (Blánquez et al. 2008; Zhang and Geissen 2012). Moreover, in most of them, only the degradation of some spiked contaminants was monitored. Recently, degradation of PhACs at pre-existent concentrations in treatments using the WRF Trametes versicolor and dealing with real effluents, such as urban and hospital wastewater and reverse osmosis concentrate from a tertiary treatment in an urban WWTP, have been reported for the first time with promising results (Badia-Fabregat et al. 2015; Cruz-Morató et al. 2014; Cruz-Morató et al. 2013a). Some of those studies were carried out under non-sterile conditions in an attempt for approaching real conditions (Cruz-Morató et al. 2014; Cruz-Morató et al. 2013a). Nonetheless, all the experiments were in batch mode, and no continuous treatment with real effluents at pre-existing PhAC concentration has been reported so far. Moreover, in none of them, the co-existing microbial community has been assessed.

On the other hand, despite the advances in the recent years, fungal treatments are still far from the optimal operational conditions for treating real non-sterile effluents. Some drawbacks, such as the growth of unwanted microorganisms, are not yet solved. Therefore, the aim of the present work is to determine if PhAC degradation at already present concentrations in a fungal bioreactor is possible under non-sterile conditions for veterinary hospital wastewater (VHW) in batch and, for the first time, in continuous operation, with special emphasis in factors that could improve it. Thus, some parameters affecting degradation are discussed, such as microbial populations and nutrient requirements. To that purpose, the bacterial and fungal populations grown inside the bioreactors were analyzed by means of PCR-denaturing gradient gel electrophoresis (DGGE) analysis for a deeper understanding of microbial interactions affecting $T$. versicolor survival.

\section{Materials and methods}

\section{Fungus, chemicals and wastewater}

Trametes versicolor (ATCC\#42530) was obtained from the American Type Culture Collection and was maintained by subculturing on petri dishes in malt extract $(2 \%)$ and agar $(1.5 \%)$ medium at $25{ }^{\circ} \mathrm{C}$. Pellets production was done as previously described by Blánquez et al. (2006).

All the pharmaceutical and the corresponding isotopically labelled standards were of high purity grade $(>90 \%)$, and they were purchased from Sigma-Aldrich (Steinheim, Germany), US Pharmacopeia USP (MD, USA), Europea Pharmacopeia EP (Strasbourg, France), Toronto Research Chemicals TRC (Ontario, Canada) and CDN isotopes (Quebec, Canada). The individual standard solutions, as well as isotopically labelled standard solutions, were prepared according to Gros et al. (2012) The solvents, high-performace liquid chromatography grade methanol, acetonitrile, water (Lichrosolv), and formic acid (98\%), were provided by Merck (Darmstadt, Germany). Glucose, ammonium tartrate dibasic, malt extract, and other chemicals were purchased from Sigma-Aldrich (Barcelona, Spain).

VHW was obtained from a veterinary hospital located in the Universitat Autònoma de Barcelona campus (Bellatera, Barcelona, Spain) the same day that each bioreactor was set up and also once a week during continuous bioreactors operation. Table $\mathrm{S} 1$ shows wastewater characterization.

\section{Fungal bioreactors and operating conditions}

Two fungal biomass air-pulsed fluidized bed glass bioreactors (1.5 L) (Blánquez et al. 2006) were set up in parallel for each experiment (batch and continuous), one inoculated with T. versicolor (B-I and C-I for batch and continuous, respectively) and the other non-inoculated as a control (B-NI and CNI). They were filled with $1.5 \mathrm{~L}$ of VHW, and temperature was set up at $25^{\circ} \mathrm{C}$, and $\mathrm{pH}$ was controlled to be constant at $4.5 \pm 0.5$ by $\mathrm{HCl} 1 \mathrm{M}$ or $\mathrm{NaOH} 1 \mathrm{M}$ addition. Samples of approximately $250 \mathrm{~mL}$, collected along bioreactors operation, were filtered by vacuum with Whatman GF/C filters and a $0.45-\mu \mathrm{m}$ nylon filter (Millipore) from which $200 \mathrm{~mL}$ were then frozen until pharmaceutical characterization, and approximately $50 \mathrm{~mL}$ were used immediately for the other routine analyses (check the "Routine analyses" section). In the batch experiment, samples for microbial community analyses were also collected and frozen at $-20^{\circ} \mathrm{C}$ in $2 \mathrm{~mL}$ eppendorfs without any processing until DNA extraction.

\section{Non-sterile fungal bioreactors operating in batch mode}

Pellets of T. versicolor were added at $2 \mathrm{~g} \mathrm{~L}^{-1}$ dry cell weight (DCW) concentration. Bioreactors were operated in fed-batch 
mode for nutrients supply. Glucose and ammonia tartrate were added in pulses of $0.6 \mathrm{~min} / \mathrm{h}$ from a concentrated stock at a rate of 277 and $0.619 \mathrm{mg} \mathrm{g} \mathrm{DCW}^{-1}$ day $^{-1}$ respectively. Addition rate was adjusted in order to avoid glucose accumulation in the media. Samples from the bioreactors media were taken on days 0,7 , and 15 .

Non-sterile fungal bioreactors operating in continuous mode

Fungal pellets were kept inside the bioreactor by means of a mesh. T. versicolor was initially added at $3.7 \mathrm{~g} \mathrm{DCW} \mathrm{L}^{-1}$. However, every 2-5 days, approximately $1 / 3$ of the biomass was replaced by fresh ones as determined by Blánquez et al. (2006). Hydraulic retention time (HRT) was 3.3 days. Initially, glucose and ammonia tartrate were added at a rate of 343 and $0.77 \mathrm{mg} \mathrm{g} \mathrm{DCW}^{-1} \mathrm{day}^{-1}$, respectively in pulses of $0.6 \mathrm{~min} / \mathrm{h}$ from a concentrated stock. Nutrient addition rate was adjusted along the process depending on the results. VHW in the feed storage tank was replaced every $2-3$ days by fresh ones stored at $4{ }^{\circ} \mathrm{C}$. VHW stored in the feed tank for 2-3 days is called "old wastewater." Twenty-four-hour samples (total volume of the effluent mixed) were taken from the effluent on days 0,5 , $10,12,14,15,17,18,21$, and 26.

\section{Analytical methods}

\section{Pharmaceuticals quantification}

The analytical procedure performed is based on the method described by Gros et al. (2012) which allows quantification of $76 \mathrm{PhACs}$. Briefly, $50 \mathrm{~mL}$ of sample were pre-concentrated by solid phase extraction (SPE) using Oasis HLB (3 cc, $60 \mathrm{mg}$ ) cartridges (Waters Corp. Mildford, MA, USA), which were previously conditioned with $5 \mathrm{~mL}$ methanol and $5 \mathrm{~mL} \mathrm{HPLC}$ grade water. Elution was done with $6 \mathrm{~mL}$ of pure methanol. The extracts were evaporated under nitrogen stream and reconstituted with $1 \mathrm{~mL}$ of methanol-water $(10: 90 \mathrm{v} / \mathrm{v})$. Lastly, $10 \mu \mathrm{L}$ of internal standard mix at $1 \mathrm{ng} \mu \mathrm{L}^{-1}$ were added in the extracts for internal standard calibration. Chromatographic separation was carried out with an ultraperformance liquid chromatography system (Waters Corp. Mildford, MA, USA), using an Acquity HSS T3 column $(50 \times 2.1 \mathrm{~mm}$ i.d. $1.7 \mu \mathrm{m}$ particle size $)$ for the compounds analyzed under positive electrospray ionization (PI) and an Acquity BEH C18 column $(50 \times 2.1 \mathrm{~mm}$ i.d., $1.7 \mu \mathrm{m}$ particle size) for the ones analyzed under negative electrospray ionization (NI), both from Waters Corporation. The UPLC instrument was coupled to $5500 \mathrm{QqLit}$, triple quadrupole linear ion trap mass spectrometer (5500 QTRAP, Applied Biosystems, Foster City, CA, USA) with a Turbo V ion spray source. Two MRM transitions per compound were recorded by using the Scheduled MRM ${ }^{\mathrm{TM}}$ algorithm, and the data were acquired and processed using the Analyst 2.1 software.

\section{Routine analyses}

Glucose concentration was measured with a biochemical analyzer YSI 2700 SELECT (Yellow Spring Instruments). Laccase activity was measured through the oxidation of 2,6dimetoxyphenol (DMP) by the enzyme laccase in a modified version of the method for the determination of manganese peroxidase of Kaal et al. (1993). The analysis process is based on the measure of the absorbance variance at $468 \mathrm{~nm}$ at $30^{\circ} \mathrm{C}$ during $2 \mathrm{~min}$ in a Varian Cary $3 \mathrm{UV} /$ Vis spectrophotometer. The reaction was done with $600 \mu \mathrm{L}$ of sample, $200 \mu \mathrm{L}$ of sodium malonate $250 \mathrm{mM}$ at $\mathrm{pH} 4.5$, and $50 \mu \mathrm{L}$ of DMP $20 \mathrm{mM}$. Activity units per liter $\left(\mathrm{U} \mathrm{L}^{-1}\right)$ are defined as the amount of DMP in micromoles per liter which are oxidized per minute ( $\mu$ mol DMP L ${ }^{-1} \min ^{-1}$ ). The molar extinction coefficient of DMP was considered as $24.8 \mathrm{mM}^{-1} \mathrm{~cm}^{-1}$ (Wariishi et al. 1992). Biomass pellet dry weight was determined after vacuum-filtering the cultures through preweighted glass-fiber filters (Whatman, Spain). The fungal amount was determined as the constant weight at $100{ }^{\circ} \mathrm{C}$. Dissolved organic carbon (DOC), total suspended solids (TSS), and volatile suspended solids (VSS) were analyzed

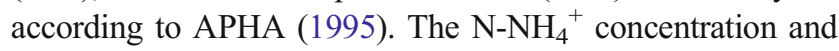
chemical oxygen demand (COD) were analyzed by using commercial kits LCH303 and LCK114 or LCK314, respectively (Hach Lange, Germany). Clorur, nitrate, nitrite, and sulfate anions were quantified by a Dionex ICS-2000 ionic chromatograph. Conductivity was determined by a CRISON MicroCM 2100 conductometer and $\mathrm{pH}$ by a $\mathrm{pH}$ meter CRISON MicropH 2001. A Microtox ${ }^{\circledR}$ bioluminiscence assay with Vibrio fisheri was used to perform acute toxicity test of filtered samples at $\mathrm{pH} 7$. The $50 \%$ effective concentration (EC50) was measured after 15 min of exposure. Effluent toxicity was expressed in toxicity units (TU), calculated as TU= 100/EC50, and an effluent was considered toxic when its TU was over 25 as it is set by local sewage disposal regulation (Generalitat de Catalunya 2003).

\section{Microbial community analysis}

Homogenized samples were taken from the bioreactors at different times and stored at $-20{ }^{\circ} \mathrm{C}$. Total genomic DNA was extracted from approximately $4 \mathrm{~mL}$ for each sample using the Fast DNA $^{\circledR}$ Spin kit for soil (MP Biomedicals, USA). Bacterial 16S rRNA genes and internal transcribed spacer (ITS) regions of fungal rRNA genes were amplified from total genomic DNA. Both cloning and band excision methodologies were used for phylogenetic assignment of the DGGE bands. Complete bacterial 16S rRNA genes were amplified for cloning and sequencing by using the forward primer Bact27-f and the universal reverse primer Uni1492-r (Weisburg et al. 1991). In the case of fungal ITS regions, the forward primer ITS1F (Gardes and Bruns 1993) and the 
reverse primer ITS4 (White et al. 1990) were employed. The thermocycling programs were as described in RodríguezRodríguez et al. (2012). For DGGE analysis, PCR products were generated using universal primers in both reactions: bacterial 16S rRNA gene primers U968-f and L1401-r (Nübel et al. 1996) and the fungal rRNA primers ITS1F and ITS2 (White et al. 1990). A 40-base GC clamp was attached to the primers U968-f and ITS1F at the $5^{\prime}$ end. The thermocycling programs were as described in RodríguezRodríguez et al. (2012). The size and amount of PCR products was estimated by electrophoresis in $1 \%$ agarose gels $(w / v)$ using a DNA marker and SYBR ${ }^{\circledR}$ Safe or ethidium bromide staining.

DGGE analysis of the PCR products was performed with either a DCode system (Bio-Rad, Hercules, CA, USA) or an INGENYphorU (Ingeny, The Netherlands) machine. Gels containing 7.5-8 \% $(w / v)$ polyacrilamide (37.5:1 acrylamide/ bis-acrylamide) with a denaturing gradient of $30-60 \%$ or 40 $80 \%$, respectively, for bacteria and $20-50$ or $25-60 \%$ for fungi was employed. Electrophoresis was performed for $16 \mathrm{~h}$ at $75-85 \mathrm{~V}$ in TAE buffer at $60^{\circ} \mathrm{C}$. Gels were then stained with silver nitrate and scanned in an Epson Perfection V750 PRO (Epson, USA) or with SYBR Gold (Invitrogen, Life Technologies) when DGGE bands were excised. Excised DGGE bands were re-amplified (22 cycles) and run in a DGGE gel until the bands were clear enough (3-6 cycles).

For cloning procedure, fragments previously amplified by PCR using the primers Bact27-f/Uni1492-r and ITS1F/ITS4 were purified by means of the PCR cleanup kit NucleoSpin Extract II (Macherey-Nagel, Germany). The fragments were then incorporated into a pGEM-T vector using the pGEM Easy Vector Systems kit (Promega, Madison, WI, USA). The vector was employed in the transformation of Escherichia coli competent cells JM109 Competent Cells (Nzytech). Positive transformants were selected after growth in LB medium supplemented with ampicillin, IPTG, and XGal. After PCR amplification with U968GC-f/L1401-r or ITS1FGC/ITS2, clones were screened in DGGE by means of comparing with the corresponding band patterns of the samples. Those clones matching different bands in the total community profile were selected, and their inserts were amplified by PCR using the pGEM-T vector-targeted sequencing primers Sp6 and T7, purified (NucleoSpin Extract II kit) and subjected to DNA sequence analysis. Inserts were bidirectionally sequenced with the primers Sp6/T7 at Eurofins MWG Operon (Ebersberg, Germany). Purification and sequencing of excised DGGE bands were performed by a commercial service (Macrogen Inc., South Korea) with the ITS1F without GC tail and R1401 primers.

For phylogenetic analysis, partial sequences were assembled using the CAP application included in the BioEdit v7.0.9 software package (Hall 1999). Chimeras were checked with Mallard 1.02 and Pintail 1.1 programs. Similarity searches for the assembled sequences were performed using the NCBI Blast search program within the GenBank database with Blast algorithm. Bacterial and fungal sequences have been submitted to the GenBank database under accession numbers KM392022-KM392055, KM355623-KM355667, and KM361323-KM361352. Those sequences that could not be deposited because their length was less than $200 \mathrm{bp}$ can be found in the supplementary material (Tables S2 and S3).

\section{Calculations and statistical analysis}

For PhAC removal calculations, those compounds detected below quantification limit (BQL) were considered to have a concentration of $1 / 2$ of the limit of quantification (LOQ) (EPA 2000). Mean and standard deviation (SD) were calculated using Microsoft ${ }^{\circledR}$ Excel 2011 functions. One-factor analysis of variance (ANOVA) and Student's $t$ tests for statistical analysis were done with Sigmaplot 11.0; differences were considered as significant at $\mathrm{p}<0.01$.

\section{Results}

\section{Non-sterile batch treatment: operational details and PhACs degradation}

Two parallel bioreactors, one inoculated with T. versicolor (BI) and the other one without fungi as a control (B-NI), were set up to assess fungal biodegradation of PhACs in a VHW under non-sterile conditions. An increase of laccase activity (around $70 \mathrm{U} \mathrm{L}^{-1}$ ) in the fungal bioreactor on day 3 was observed, but after 7 days, no activity was detected (Fig. S1A), which led us to think that $T$. versicolor was not active. Initially, glucose was added at $276 \mathrm{mg} \mathrm{g} \mathrm{DCW}^{-1}$ day $^{-1}$ as previously calculated (Casas et al. 2013) and was totally consumed (Fig. S1). On day 5, glucose addition was increased to $1453 \mathrm{mg} \mathrm{g}$ $\mathrm{DCW}^{-1}$ day $^{-1}$ when pellets started to disaggregate parallel to the laccase activity reduction. However, glucose addition rate was reduced again on day 8 when it was observed that glucose started to accumulate in the media. COD was around $400 \mathrm{mg}$ $\mathrm{O}_{2} \mathrm{~L}^{-1}$ until day 7 , reaching $2930 \mathrm{mg} \mathrm{O}_{2} \mathrm{~L}^{-1}$ after glucose input was augmented (Fig. S1A). However, it was far below the $11,560 \mathrm{mg} \mathrm{O}_{2} \mathrm{~L}^{-1}$ of COD accumulated in the control reactor at the end of the experiment (Fig. S1B), which indicates that metabolic products accumulated in it. VHW had very low acute toxicity, with a TU value in the Microtox ${ }^{\circledR}$ analysis of 1.64. After the treatment, B-NI bioreactor had a toxicity of $0.66 \mathrm{TU}$, whereas the effluent after fungal treatment showed no toxicity at all.

Regarding PhACs, 76 pharmaceutical compounds and some of their metabolites were analyzed in both bioreactors at 3 time points: at the beginning, after 7 days, and at the end of the treatment (15 days). They were selected according to 
their widespread presence in wastewaters (Gros et al. 2012). Among them, 45 were detected in the VHW and/or in the effluent of the treatments. Antibiotics, anti-inflammatories, and analgesics were the compounds detected at higher concentrations (Fig. 1, initial time). Overall, antibiotics were found at $34.4 \mu \mathrm{g} \mathrm{L}^{-1}$. The antibiotics found at highest concentration were cefalexin, ciprofloxacin, metronidazole, trimethoprim, and tetracycline. Analgesics and anti-inflammatories were found at $1.16 \mu \mathrm{g} \mathrm{L}^{-1}$, with ketoprofen as the PhAC detected at highest concentration. Psychiatric drugs were also found among the highest concentrations $\left(2.26 \mu \mathrm{g} \mathrm{L}^{-1}\right)$ with acridone, a carbamazepine metabolite, as the compound at the highest concentration.

Table S4 shows initial concentration and removal percentages of detected PhACs. In the B-I reactor, removal of $66 \%$ of total analyzed compounds was achieved at the end of the treatment, whereas in the control B-NI reactor, no removal was observed (Fig. 1). Some antibiotics (with an overall removal of $57 \%$ after 7 days and until $92 \%$ after 14 days in B-I, and negligible removal in B-NI) such as ciprofloxacin, metronidazole and its hydroxilated metabolite, $\beta$-blocker carazolol, psychiatric drug diazepam, and anti-inflammatory naproxen were totally or partially removed in the fungal bioreactor, whereas no removal was observed in the control bioreactor. Other compounds were equally degraded in B-I and B-NI, among which were the antibiotics cefalexin and tetracyclin, psychiatric drugs sertraline and paroxetine, lipid regulator gemfibrozil, anti-hypertensive amlodipine, and diuretic furosemide. Some PhACs, like the antibiotics dimetridazole, azythromycin, and ronidazole and psychiatric drug olanzapine, were not significantly removed in any of the reactors. For some compounds, such as anti-inflammatories ketoprofen and piroxicam and $\beta$-blockers metoprolol, propranolol, and nadolol, their concentration increased after the treatments, but more in B-I bioreactor than in B-NI. Ketoprofen increase (until 5.7 and $2.3 \mu \mathrm{g} \mathrm{L}^{-1}$ at 15 days in B-I and B-NI reactors, respectively) even masks degradation of other anti-inflammatories in the overall removal calculation. The concentration of psychiatric drug carbamazepine and its metabolite acridone (detected already up to $1.07 \mu \mathrm{g} \mathrm{L}^{-1}$ initially), as well as lipid regulators atorvastatin and pravastatin and the antibiotic ciprofloxacin, increased preferentially in B-NI. Finally, only desloratadine was better removed in B-NI than in B-I after 7 days.

\section{Evolution of bacterial and fungal populations in batch bioreactors}

Results for evolution of microbial communities in the batch bioreactors B-I and B-NI are shown in Fig. 2 and Tables 1 and 2. It can be seen that the band corresponding to $T$. versicolor (F10) in B-I bioreactor almost disappeared after 15 days. Regarding other fungi, sequences related to the Ascomycota Fusarium, Trichoderma, Rhinocladiella, and Phialemonium were found in the B-I at both 7 and 15 days, instead of those related to the Basidiomycota Trichosporon, the main fungi in the B-NI. Some yeasts affiliated to Galactomyces were also detected at B-NI. It should be noted that higher diversity does not imply higher concentration. In the present work, microbial populations have only been identified but not quantified.

Regarding bacteria, microorganisms belonging to the orders Burkholderiales ( $\beta$-proteobacteria), Xanthomonadales ( $\gamma$-proteobacteria), and Rhizobiales ( $\alpha$-proteobacteria) were detected at B-I at the sample on day 7. Bacteria profiles of B-I and B-NI on day 15 were very similar. In both of them, two main bands were observed, belonging to $\gamma$ - and $\alpha$ proteobacteria (Enterobacteriales and Rhodospirillales, respectively).

\section{Non-sterile continuous treatment: operational details and PhACs degradation}

Results obtained in batch experiments encouraged us to further treat VHW in continuous mode under non-sterile conditions. The same setting of two parallel bioreactors, one inoculated with pellets of T. versicolor (C-I) and the other one non-
Fig. 1 Evolution of total PhACs grouped by therapeutic classes in the batch treatment inoculated with $T$. versicolor $(\mathrm{B}-\mathrm{I})$ and in the non-inoculated control bioreactor (B-NI) at 7 and 15 days of treatment in comparison with the initial concentration (the same for both reactors)

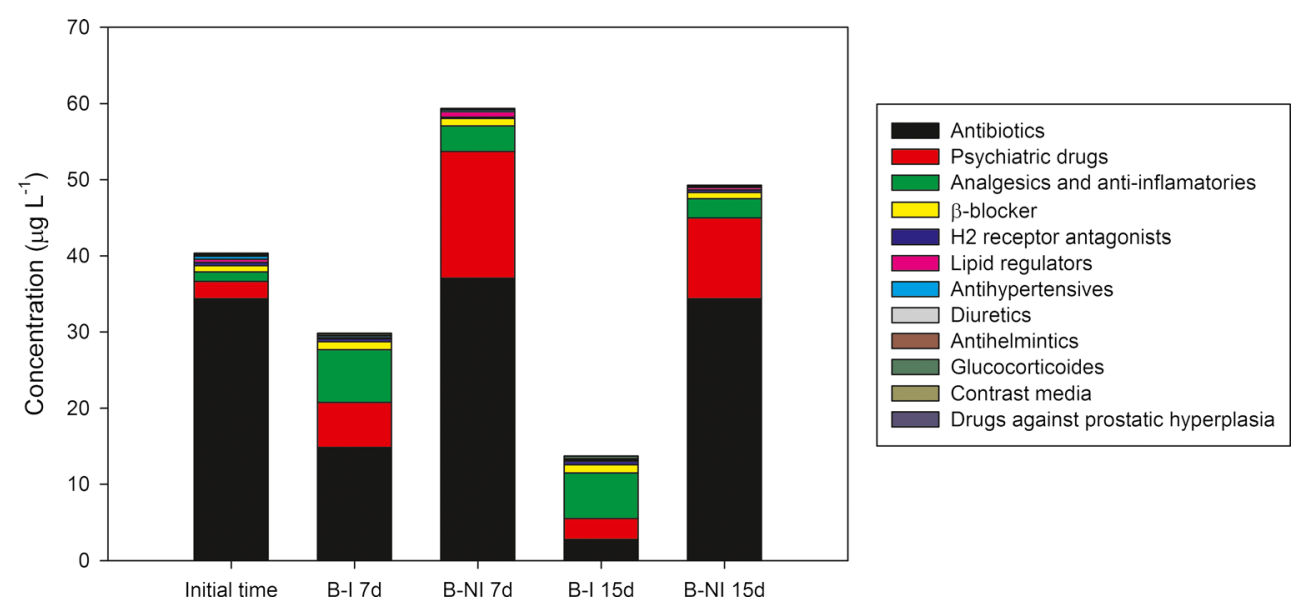


Fig. 2 DGGE profiles of PCR amplified a bacterial 16S rRNA fragment and $\mathbf{b}$ fungal ITS fragment. Samples are from the non-sterile batch bioreactor. $I$ correspond to bioreactor inoculated with $T$. versicolor and $N I$ to non-inoculated reactor. 0,1 , 7 , and 15 correspond to the time of sampling
A) BACTERIA

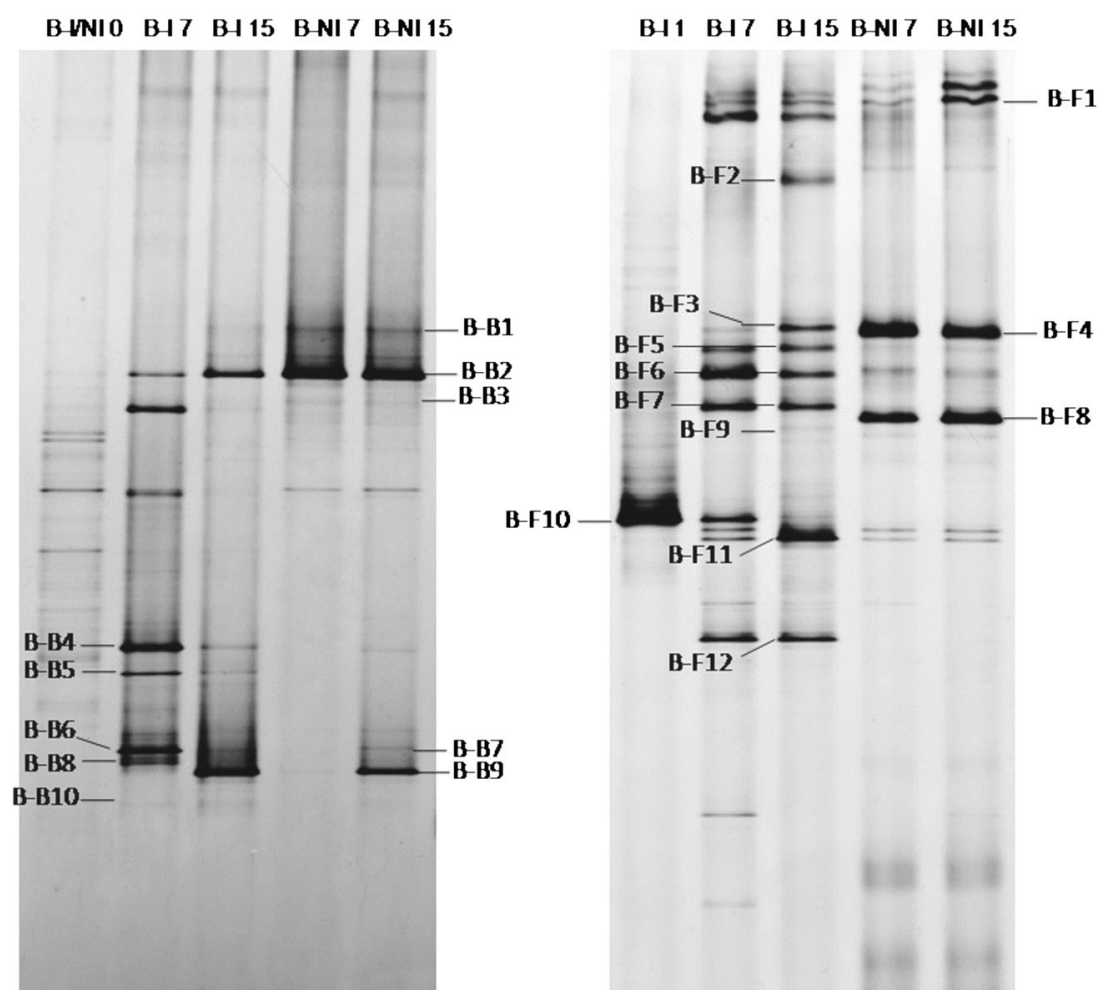

inoculated as control (C-NI), was performed. Bioreactors were operated at an HRT of 3.3 days. From the DGGE results of T. versicolor predominance, cellular retention time (CRT) was fixed between 6 and 15 days, with partial biomass renovation every $2-5$ days, depending on visual evolution of the pellets consistency. As shown in Fig. S2A and S2B, initial addition of glucose was $343 \mathrm{mg} \mathrm{g} \mathrm{DCW}^{-1}$ day $^{-1}$, in a similar amount per DCW as in the batch bioreactors, but it was increased until $1040 \mathrm{mg} \mathrm{g} \mathrm{DCW}^{-1}$ day $^{-1}$, thus trying to avoid fungal lysis (Fig. 3). However, fungal biomass was not stabilized until the addition of a pulse of $4.9 \mathrm{~g}$ of ammonia tartrate on day 12 and the following decrease in the $\mathrm{C} / \mathrm{N}$ ratio in the nutrient stock after day 19, when ammonia from the pulse was depleted. The amount of ammonium tartrate used for the pulse and $\mathrm{C} / \mathrm{N}$ ratio in the feeding nutrient stock corresponded to the one used when working in synthetic media (Marco-Urrea et al. 2010), being glucose added at $480-1040 \mathrm{mg} \mathrm{g} \mathrm{DCW}^{-1}$ day $^{-1}$ and ammonium tartrate at $217-433 \mathrm{mg} \mathrm{g} \mathrm{DCW}{ }^{-1}$ day $^{-1}$ from day 19 onward. Since the change in the $\mathrm{C} / \mathrm{N}$ ratio on day 12 until the end of operation on day 26, the amount of fungal biomass in the C-I reactor was stabilized. Laccase activity oscillated between 0 and $90 \mathrm{U} \mathrm{L}^{-1}$ until day 19. From that moment onward, laccase activity remained below $10 \mathrm{U} \mathrm{L}^{-1}$ despite being the period when fungal pellet biomass was maintained. Acute toxicity was analyzed by Microtox ${ }^{\circledR}$, and TU for veterinary hospital fresh wastewater were 10, 11, and 20 for samples at initial time, 10 and 18 days, respectively.
However, all of them were below the value of $25 \mathrm{TU}$ when an effluent is considered as toxic (Generalitat de Catalunya 2003). Old wastewater stored in the storage tank decreased their toxicity to $1-2 \mathrm{TU}$, denoting some degradation in the storage tank. At 11 days, toxicity in the reactors was also 1-2 TU, while after 26 days, acute toxicity was totally removed (Table S5).

Regarding PhACs degradation, no statistical significant removal was detected during the operation except at the last part of the continuous treatment (from day 21 to 26), when removal in C-I bioreactor was $44 \%$, whereas in the C-NI, global concentration of PhACs increased (Fig. 4). It is noteworthy that no stationary state was achieved because different nutrient additions were being tested during the process to determine favorable conditions for fungal survival. Therefore, removal data for continuous treatments were calculated at the best performance point of fungal bioreactors, which was at the end of the operation (26 days). However, the decreasing tendency in PhAC concentration in C-I can be observed already from the 14th day, just after ammonia pulse, when lysis of $T$. versicolor was stopped. Analgesics and anti-inflammatories were the $\mathrm{PhACs}$ detected at higher concentration in the samplings for continuous treatment (Table S6). Concentration decrease after ammonia addition can be observed as well in their profile (Fig. S3). That profile is dominated by salycilic acid, the compound detected at highest concentration. Regarding antibiotics, their concentration was much lower than in the previous 
Table 1 Phylogenetic affiliation of 16S rRNA bacterial sequences corresponding to the different bands of DGGE patterns in batch and continuous treatments

\begin{tabular}{|c|c|c|c|c|c|c|}
\hline $\begin{array}{l}\text { DGGE } \\
\text { Band }\end{array}$ & $\begin{array}{l}\text { Seq. } \\
\text { length }\end{array}$ & Closest relative $^{\mathrm{a}}$ & $\begin{array}{l}\text { Accession } \\
\text { number }\end{array}$ & $\begin{array}{l}\text { Length } \\
\text { coverage }\end{array}$ & $\begin{array}{l}\text { Identity } \\
(\%)\end{array}$ & Class/Order ${ }^{\mathrm{b}}$ \\
\hline B-B1 & 1464 & Klebsiella pneumoniae strain Kp52.145 & FO834906 & $1460 / 1464$ & 99 & $\begin{array}{l}\gamma \text {-Proteobacterial } \\
\quad \text { Enterobacteriales }\end{array}$ \\
\hline B-B2 & 1465 & $\begin{array}{l}\text { Enterobacter sp. LRC22 } \\
\text { Raoultella ornithinolytica strain B6 }\end{array}$ & $\begin{array}{l}\text { JF772056 } \\
\text { CP004142 }\end{array}$ & $\begin{array}{l}1463 / 1465 \\
1462 / 1465\end{array}$ & 99 & $\begin{array}{l}\gamma \text {-Proteobacterial } \\
\quad \text { Enterobacteriales }\end{array}$ \\
\hline B-B3 & 1463 & Klebsiella pneumoniae strain MBR11 & JX966429 & $1462 / 1464$ & 99 & $\begin{array}{l}\gamma-\text { Proteobacterial } \\
\quad \text { Enterobacteriales }\end{array}$ \\
\hline B-B4 & 1469 & $\begin{array}{l}\text { Luteibacter sp. enrichment culture clone } 35 \mathrm{Fe} 215 \\
\text { Dyella yeojuensis strain rif } 200829\end{array}$ & $\begin{array}{l}\text { KF287733 } \\
\text { FJ527678 }\end{array}$ & $\begin{array}{l}1464 / 1469 \\
1453 / 1469\end{array}$ & 99 & $\begin{array}{l}\gamma \text {-Proteobacterial } \\
\quad \text { Xanthomonadales }\end{array}$ \\
\hline B-B5 & 1409 & $\begin{array}{l}\text { Uncultured Agrobacterium sp. clone CBXB23 } \\
\text { Agrobacterium tumefaciens strain NBRC } 15293\end{array}$ & $\begin{array}{l}\text { GU569105 } \\
\text { AB680824 }\end{array}$ & $\begin{array}{l}1395 / 1409 \\
1392 / 1409\end{array}$ & 99 & $\begin{array}{l}\alpha \text {-Proteobacterial } \\
\quad \text { Rhizobiales }\end{array}$ \\
\hline $\begin{array}{l}\text { B-B8 } \\
\text { B-B10 }\end{array}$ & 1457 & Burkholderia gladioli strain CACua-73 & HQ023278 & $\begin{array}{l}1456 / 1457 \\
1438 / 1457\end{array}$ & 99 & $\begin{array}{c}\text { B-Proteobacterial } \\
\text { Burkholderiales }\end{array}$ \\
\hline B-B7 & 1414 & Acidomonas methanolica strain: NBRC 104435 & AB682176 & $1406 / 1414$ & 99 & $\begin{array}{l}\alpha \text {-Proteobacterial } \\
\quad \text { Rhodospirillales }\end{array}$ \\
\hline B-B9 & 1414 & Acidomonas methanolica strain: NBRC 104435 & AB682176 & $1410 / 1414$ & 99 & $\begin{array}{l}\alpha \text {-Proteobacterial } \\
\quad \text { Rhodospirillales }\end{array}$ \\
\hline C-B2 & 334 & Uncultured bacterium clone ncd $2574 \mathrm{c} 06 \mathrm{c} 1$ & JF226179 & $329 / 334$ & 99 & Unclassified proteobacteria \\
\hline C-B4 & 339 & $\begin{array}{l}\text { Uncultured soil bacterium clone SM11 } \\
\text { Micavibrio aeruginosavorus EPB }\end{array}$ & $\begin{array}{l}\text { EU339599 } \\
\text { CP003538 }\end{array}$ & $\begin{array}{l}334 / 339 \\
298 / 325\end{array}$ & $\begin{array}{l}99 \\
92\end{array}$ & Unclassified proteobacteria \\
\hline C-B5 & 337 & $\begin{array}{l}\text { Uncultured alpha proteobacterium } \\
\text { Acidocella aluminiidurans strain NBRC } 104303\end{array}$ & $\begin{array}{l}\text { AB809968 } \\
\text { NR_114266 }\end{array}$ & $\begin{array}{l}337 / 337 \\
336 / 337\end{array}$ & $\begin{array}{l}100 \\
99\end{array}$ & $\begin{array}{l}\alpha \text {-Proteobacterial } \\
\quad \text { Rhodospirillales }\end{array}$ \\
\hline C-B6 & 351 & $\begin{array}{l}\text { Klebsiella sp. Enrichment culture clone F-2 } \\
\text { Klebsiella pneumoniae str. Kp } 52.145\end{array}$ & $\begin{array}{l}\text { KJ465989 } \\
\text { FO834906 }\end{array}$ & $351 / 351$ & 100 & $\begin{array}{l}\gamma \text {-Proteobacterial } \\
\quad \text { Enterobacteriales }\end{array}$ \\
\hline C-B7 & 377 & $\begin{array}{l}\text { Klebsiella sp. Enrichment culture clone F-2 } \\
\text { Klebsiella pneumoniae str. Kp } 52.145\end{array}$ & $\begin{array}{l}\text { KJ465989 } \\
\text { FO834906 }\end{array}$ & $377 / 377$ & 100 & $\begin{array}{l}\gamma \text {-Proteobacterial } \\
\quad \text { Enterobacteriales }\end{array}$ \\
\hline C-B8 & 346 & Uncultured bacterium clone ZBAF2-82 & HQ682040 & $346 / 347$ & 99 & Unclassified Proteobacteria \\
\hline C-B9 & 317 & Uncultured bacterium clone ZBAF2-82 & HQ682040 & $317 / 317$ & 100 & Unclassified Proteobacteria \\
\hline $\mathrm{C}-\mathrm{B} 10$ & 340 & $\begin{array}{l}\text { Uncultured bacterium clone UVaBiofilter-V26 } \\
\text { Prosthecobacter fluviatilis strain HAQ-1 }\end{array}$ & $\begin{array}{l}\text { KJ002532 } \\
\text { NR_041608 }\end{array}$ & $\begin{array}{l}335 / 340 \\
327 / 341\end{array}$ & $\begin{array}{l}99 \\
96\end{array}$ & Verrucomicrobiae/ Verrucomicrobiales \\
\hline C-B11 & 335 & Uncultured bacterium clone eff 4 & JN245720 & $331 / 335$ & 99 & Unclassified $\alpha$-Proteobacteria \\
\hline C-B12 & 341 & $\begin{array}{l}\text { Bacterium NLAE-zl-P34 } \\
\text { Acetoanaerobium noterae strain NOT-3 }\end{array}$ & $\begin{array}{l}\text { JQ606884 } \\
\text { NR_104848 }\end{array}$ & $341 / 341$ & 100 & Clostridia/ Clostridiales \\
\hline C-B13 & 341 & $\begin{array}{l}\text { Acetoanaerobium sp. WJDL-Y2 } \\
\text { Acetoanaerobium noterae strain NOT-3 }\end{array}$ & $\begin{array}{l}\text { KF176997 } \\
\text { NR_104848 }\end{array}$ & $340 / 341$ & 99 & Clostridial Clostridiales \\
\hline C-B14 & 353 & $\begin{array}{l}\text { Uncultured bacterium A1Q1_fos_291 } \\
\text { Acetoanaerobium noterae strain NOT-3 }\end{array}$ & $\begin{array}{l}\text { JX649891 } \\
\text { NR_104848 }\end{array}$ & $\begin{array}{l}353 / 353 \\
352 / 353\end{array}$ & $\begin{array}{l}100 \\
99\end{array}$ & Clostridial Clostridiales \\
\hline C-B15 & 335 & Parachlamydia acanthamoebae UV-7 strain UV-7 & NR_074972 & $335 / 335$ & 100 & Chlamydiael Chlamydiales \\
\hline C-B16 & 336 & $\begin{array}{l}\text { Uncultured Peptostreptococcaceae } \\
\text { bacterium clone CatInokulum014 }\end{array}$ & KJ600240 & $336 / 336$ & 100 & Clostridia/ Clostridiales \\
\hline C-B17 & 336 & Micavibrio aeruginosavorus EРB & СР003538 & $336 / 336$ & 100 & Unclassified proteobacteria \\
\hline C-B18 & 327 & Micavibrio aeruginosavorus EРB & CP003538 & $327 / 327$ & 100 & Unclassified proteobacteria \\
\hline C-B19 & 338 & $\begin{array}{l}\text { Uncultured bacterium isolate DGGE gel band MFC7-1 } \\
\text { Clostridium sticklandii str. DSM } 519\end{array}$ & $\begin{array}{l}\text { EU272913 } \\
\text { FP565809 }\end{array}$ & $\begin{array}{l}337 / 338 \\
335 / 338\end{array}$ & 99 & Clostridia/ Clostridiales \\
\hline C-B21 & 319 & Uncultured alpha proteobacterium clone S-30-48 & KF827415 & $313 / 319$ & 98 & Unclassified Proteobacteria \\
\hline C-B22 & 305 & $\begin{array}{l}\text { Uncultured bacterium clone ncd1306f09c1 } \\
\text { Dongia mobilis strain LM22 }\end{array}$ & $\begin{array}{l}\text { JF107942 } \\
\text { NR_116676 }\end{array}$ & $\begin{array}{l}272 / 307 \\
263 / 300\end{array}$ & $\begin{array}{l}89 \\
88\end{array}$ & Unclassified Proteobacteria \\
\hline C-B23 & 331 & $\begin{array}{l}\text { Burkholderia sp. WR } 43 \\
\text { Burkholderia nodosa strain Br3470 }\end{array}$ & $\begin{array}{l}\text { AB365791 } \\
\text { AM284972 }\end{array}$ & $\begin{array}{l}327 / 331 \\
325 / 331\end{array}$ & $\begin{array}{l}99 \\
98\end{array}$ & $\begin{array}{c}\beta \text {-Proteobacterial } \\
\quad \text { Burkholderiales }\end{array}$ \\
\hline $\mathrm{C}-\mathrm{B} 25$ & 304 & $\begin{array}{l}\text { Uncultured Verrucomicrobiaceae bacterium } \\
\text { clone A03-06C }\end{array}$ & FJ542838 & $292 / 304$ & 96 & $\begin{array}{l}\text { Verrucomicrobiael } \\
\quad \text { Verrucomicrobiales }\end{array}$ \\
\hline C-B26 & 333 & $\begin{array}{l}\text { Burkholderia sp. WR43 } \\
\text { Burkholderia nodosa strain Br3470 }\end{array}$ & $\begin{array}{l}\text { AB365791 } \\
\text { AM284972 }\end{array}$ & $\begin{array}{l}330 / 333 \\
328 / 333\end{array}$ & $\begin{array}{l}99 \\
98\end{array}$ & $\begin{array}{l}\text { } \beta \text {-Proteobacterial } \\
\text { Burkholderiales }\end{array}$ \\
\hline
\end{tabular}

${ }^{\mathrm{a}}$ Closest organism at GenBank and, when possible, cultured closest match

${ }^{\mathrm{b}}$ Classified using the Ribosomal Database Project (RDP) 
sampling campaign for batch bioreactors. The compounds detected at higher concentrations were metronidazole and its hydroxylated metabolite, mainly in the wastewater fed during day 18 to 26 . When concentration in the entrance was lower (days $0-18$ ), no statistically significant degradation was observed, neither in C-I nor in C-NI bioreactors. However, after the 21 st day, around $40-50 \%$ degradation was detected in C-I bioreactor, whereas an increase in the concentration was observed in C-NI. The low biodegradable contrast media iopromide was only detected in the entrance wastewater from day 10 to 18 . The concentration of iopromide in the effluent of $\mathrm{C}-\mathrm{I}$ and C-NI increased progressively from the 10th to 15 th day, followed by a decrease in C-I due to fungal degradation, whereas in C-NI, it continued to increase (Fig. S3). Psychiatric drugs had the same concentration profile in the entrance as iopromide, with a peak of approximately $2.5 \mu \mathrm{g} \mathrm{L} \mathrm{L}^{-1}$ between the 10th and 18th due to the increase of diazepam in the VHW. That increase was not observed in the effluent of the reactors, which showed a diazepam concentration of around 0.1$0.3 \mu \mathrm{g} \mathrm{L}^{-1}$. However, diazepam degradation can not be assured as adsorption in the sampling system was observed previously (Badia-Fabregat et al. 2015). Carbamazepine was never detected in the fed wastewater; however, it was detected in the effluent of the bioreactors. Those increases in the concentration of some compounds are discussed in the "Removal of PhACs and toxicity in the fungal treatment and importance of the addition of external nutrients section." Diuretic furosemide was highly removed in the fungal bioreactor ( $83 \%$ at 26 days), whereas its concentration increased in the C-NI reactor in the second half of the treatment. The $\mathrm{H} 2$ receptors antagonist ranitidine was neither detected in the fresh water, but its concentration increased in the storage tank and also in the C-NI bioreactor. However, in the C-I bioreactor, it was totally removed. Other changes in $\mathrm{PhAC}$ concentration were detected between fresh and old wastewater in the storage tank (Table S6). In the antihypertensives amlodipine and irbesartan, similar deconjugation processes might occur.

Taking into account removal percentages on day 26 (Table S6), PhACs can be grouped as compounds better removed in C-I than in C-NI (i.e., salicylic acid, metronidazole, diazepam, furosemide, clopidrogel and ranitidine), equally removed in both reactors (ibuprofen), and not statistically significantly removed in any of them (ketoprofen). Among those whose concentration increased, piroxicam, diclofenac, and carbamazepine increased more in C-I and metronidazole-OH increased more in C-NI.

\section{Evolution of bacterial and fungal populations in continuous bioreactors}

Figure 5 shows the DGGE profiles of fungi and bacteria, respectively. Phylogenetic affiliation of the selected bands can be found at Tables 1 and 2. T. versicolor was detected in all samples. Liquid sample at day 1 of C-NI was discarded for further analysis due to PCR contamination suspicion. Other fungi detected at C-I and C-NI bioreactors were similar, mainly Candida spp. and Fusarium spp. A fungus belonging to Xylariales $s p$. and an unknown fungus ( $88 \%$ of identity with Ophiostoma) was grown at C-NI as well. Some sequences, such as that belonging to F11 band, could not be cleaned enough for sequencing. Similar bacterial communities were also found at C-I and C-NI, as what happened with fungi. Thus, many unclassified proteobacteria, Enterobacteriales $s p$., Burkholderiales sp., and Verrucomicrobiales sp. were detected. Chlamydiales sp. and Rhodospirillales were also found at day 26 at C-NI. Both fungal and bacterial diversity (accounted as diversity of DGGE bands) in the continuous reactors increased along the treatment.

\section{Discussion}

\section{PhAC concentration in the VHW}

Although urban and human hospital wastewaters have been extensively studied regarding PhAC concentration (Verlicchi et al. 2012; Verlicchi et al. 2010), a VHW has been characterized for the first time in the present study. As shown in Table S1, regarding physicochemical characteristics, VHW has the same values than average urban wastewater. The effluent presented certain inter-day variability regarding PhAC concentration, with particular peaks of high concentration of i.e., the contrast media iopromida, the psychiatric drug diazepam, the antibiotics metronidazole, cefalexin, and ciprofloxacin, and the analgesic salycilic acid. However, in general, antibiotics, anti-inflammatories, and analgesics were the compounds detected at higher concentrations in all the samples for both batch and continuous treatments (Fig. 1, initial time, and Tables S4 and S5). This is in agreement with the type of drugs mostly prescribed at the hospital, according to the veterinary hospital staff. However, although not prescribed for veterinary treatment, psychiatric drugs were also found among the highest concentrations, even though they were lower than those reported in hospital and urban wastewaters (CruzMorató et al. 2014; Cruz-Morató et al. 2013a; Gros et al. 2012; Santos et al. 2013) because wastewater from the human activities of the veterinary hospital was collected as well. The overall antibiotic concentration was in the same order of magnitude to what is reported for human hospitals, with an average value of $11 \mu \mathrm{g} \mathrm{L}^{-1}$ (Verlicchi et al. 2010). Ciprofloxacin and metronidazole, the antibiotics found at highest concentrations, are also among those highly detected at hospital wastewaters (Santos et al. 2013; Verlicchi et al. 2010). Analgesics and anti-inflammatories were at lower concentration than expected (1.16-5.66 $\left.\mu \mathrm{g} \mathrm{L}^{-1}\right)$, since they are reported to be at concentrations around $100 \mu \mathrm{g} \mathrm{L}^{-1}$ in hospital wastewaters 
Table 2 Phylogenetic affiliation of ITS fungal sequences corresponding to the different bands of DGGE patterns in batch and continuous treatments

\begin{tabular}{|c|c|c|c|c|c|}
\hline DGGE band & Seq. length & Closest relative $^{\mathrm{a}}$ & Accession number & Length coverage & Identity $(\%)$ \\
\hline B-F1 & 368 & Galactomyces candidum strain CBS 180.33 & JN974289 & $366 / 368$ & 99 \\
\hline B-F2 & 603 & Pichia guilliermondii strain S0201 & EF643576 & $601 / 603$ & 99 \\
\hline B-F3 & 552 & Phialemonium curvatum strain: CBS 490.82 & AB278180 & $547 / 552$ & 99 \\
\hline B-F4 & 527 & $\begin{array}{l}\text { Uncultured fungus isolate RFLP27 } \\
\text { Trichosporon laibachii strain CBS } 5790\end{array}$ & $\begin{array}{l}\text { AF461588 } \\
\text { EU559348 }\end{array}$ & $\begin{array}{l}527 / 527 \\
511 / 511\end{array}$ & 100 \\
\hline B-F5 & 565 & Fusarium solani strain 6.M8 & FJ224382 & 559562 & 99 \\
\hline B-F6 & 563 & $\begin{array}{l}\text { Uncultured Fusarium sp. clone PA1912 } \\
\text { Fusarium solani culture-collection UOA/HCPF:12649 }\end{array}$ & $\begin{array}{l}\text { GQ280338 } \\
\text { KC254048 }\end{array}$ & $\begin{array}{l}562 / 563 \\
557 / 565\end{array}$ & 99 \\
\hline B-F7 & 565 & Fusarium solani culture-collection UOA/HCPF:12649 & KC254048 & $565 / 565$ & 100 \\
\hline B-F8 & 524 & $\begin{array}{l}\text { Uncultured eukaryote clone N414T_268 } \\
\text { Trichosporon dermatis culture-collection UOA/HCPF }\end{array}$ & $\begin{array}{l}\text { GU941914 } \\
\text { KC254108 }\end{array}$ & $\begin{array}{l}521 / 524 \\
519 / 524\end{array}$ & 99 \\
\hline B-F9 & 523 & $\begin{array}{l}\text { Trichosporonales sp. LM88 } \\
\text { Trichosporon jirovecii strain ATCC } 34499\end{array}$ & $\begin{array}{l}\text { EF060462 } \\
\text { HM802131 }\end{array}$ & $\begin{array}{l}523 / 524 \\
510 / 510\end{array}$ & $\begin{array}{l}99 \\
100\end{array}$ \\
\hline B-F10 & 619 & Trametes versicolor sample ID: MQN028 & AB811868 & $619 / 619$ & 100 \\
\hline B-F11 & 612 & Rhinocladiella similis culture-collection UOA/HCPF:11700 & KC254071 & $610 / 612$ & 99 \\
\hline B-F12 & 599 & Trichoderma asperellum strain ZJSX5001 & JQ040323 & $598 / 599$ & 99 \\
\hline $\mathrm{C}-\mathrm{F} 1$ & 179 & Candida sp. NRRL Y-27161 & DQ911459 & $164 / 164$ & 100 \\
\hline C-F2 & 227 & Candida palmioleophila strain ATCC 96299 & KC479687 & $227 / 227$ & 100 \\
\hline $\mathrm{C}-\mathrm{F} 4$ & 188 & $\begin{array}{l}\text { Uncultured eukaryote clone NS31T_257 } \\
\text { Rhodotorula mucilaginosa strain ATCC } 4056\end{array}$ & $\begin{array}{l}\text { KJ182680 } \\
\text { KC881070 }\end{array}$ & $188 / 188$ & 100 \\
\hline C-F5 & 172 & $\begin{array}{l}\text { Xylariales sp. HP-2011b } \\
\text { Phialemonium curvatum strain UTHSC R-3447 }\end{array}$ & $\begin{array}{l}\text { HE599293 } \\
\text { AY818323 }\end{array}$ & $\begin{array}{l}172 / 172 \\
171 / 172\end{array}$ & $\begin{array}{l}100 \\
99\end{array}$ \\
\hline C-F6 & 172 & $\begin{array}{l}\text { Xylariales sp. HP-2011b } \\
\text { Phialemonium curvatum strain UTHSC R-3447 }\end{array}$ & $\begin{array}{l}\text { HE599293 } \\
\text { AY818323 }\end{array}$ & $\begin{array}{l}172 / 172 \\
171 / 172\end{array}$ & $\begin{array}{l}100 \\
99\end{array}$ \\
\hline C-F7 & 213 & $\begin{array}{l}\text { Exophiala sp. CCFEE } 5933 \\
\text { Exophiala equina CBS } 119.23\end{array}$ & $\begin{array}{l}\text { JX681050 } \\
\text { NR_111627 }\end{array}$ & $213 / 213$ & 100 \\
\hline C-F8 & 188 & Fusarium solani voucher CEQCA-O0484 & KC771504 & $188 / 188$ & 100 \\
\hline C-F9 & 188 & Fusarium solani voucher CEQCA-O0484 & KC771504 & $188 / 188$ & 100 \\
\hline C-F10 & 188 & $\begin{array}{l}\text { Uncultured soil fungus isolate DGGE gel band F3 } \\
\text { Fusarium solani strain DAOM } 215455\end{array}$ & $\begin{array}{l}\text { KJ562397 } \\
\text { JN942906 }\end{array}$ & $188 / 188$ & 100 \\
\hline C-F13 & 220 & Trametes versicolor culture-collection ICMP:19973 & KF727428 & $220 / 220$ & 100 \\
\hline C-F14 & 202 & Trametes versicolor culture-collection ICMP:19973 & KF727428 & $202 / 202$ & 100 \\
\hline C-F15 & 222 & Trametes versicolor culture-collection ICMP:19973 & KF727428 & $222 / 222$ & 100 \\
\hline C-F16 & 241 & $\begin{array}{l}\text { Exophiala oligosperma strain MH2012-17 } \\
\text { Exophiala oligosperma CBS } 725.88\end{array}$ & $\begin{array}{l}\text { AB777520 } \\
\text { NR_111134 }\end{array}$ & $\begin{array}{l}239 / 239 \\
239 / 240\end{array}$ & $\begin{array}{l}100 \\
99\end{array}$ \\
\hline C-F17 & 239 & $\begin{array}{l}\text { Exophiala oligosperma strain MH2012-17 } \\
\text { Exophiala oligosperma CBS } 725.88\end{array}$ & $\begin{array}{l}\text { AB777520 } \\
\text { NR_111134 }\end{array}$ & $\begin{array}{l}239 / 239 \\
239 / 240\end{array}$ & $\begin{array}{l}100 \\
99\end{array}$ \\
\hline C-F18 & 212 & $\begin{array}{l}\text { Uncultured exophiala clone CBB3.14 } \\
\text { Exophiala moniliae CBS } 520.76\end{array}$ & $\begin{array}{l}\text { KC876175 } \\
\text { NR_111448 }\end{array}$ & $\begin{array}{l}200 / 212 \\
200 / 215\end{array}$ & $\begin{array}{l}94 \\
93\end{array}$ \\
\hline C-F19 & 202 & $\begin{array}{l}\text { Heterobasidion sp. NL-2013 isolate PFC } 5320 \\
\text { Heterobasidion parviporum strain B1142 }\end{array}$ & $\begin{array}{l}\text { KC492958 } \\
\text { GQ162421 }\end{array}$ & $202 / 202$ & 100 \\
\hline C-F20 & 201 & Trichoderma asperellum strain TR08 & AB935955 & $201 / 201$ & 100 \\
\hline C-F21 & 132 & Ophiostoma stenoceras strain CBS103.78 & AF484449 & $106 / 121$ & 88 \\
\hline
\end{tabular}

${ }^{\mathrm{a}}$ Closest organism at GenBank and, when possible, cultured closest match

(Cruz-Morató et al. 2014; Verlicchi et al. 2010). Overall $\mathrm{PhACs}$ levels were in general lower than those reported for hospital wastewaters (Kovalova et al. 2012; Verlicchi et al. 2010) probably due to the higher use of water (and therefore dilution of wastewater) for cleaning the veterinary facilities, and the fact that urine from big animals (i.e., horses) was collected with straw and disposed separately. In conclusion, although not an extensive sampling campaign has been carried out for the VHW, the results hereby presented pointed that the type of PhACs and the range of concentration in that kind of 


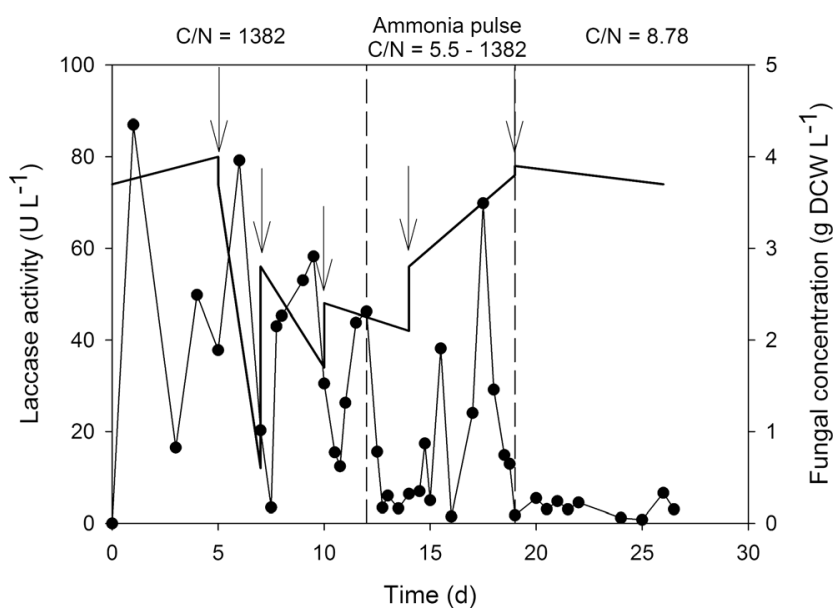

Fig. 3 Profiles of (black circle) laccase activity and (horizontal bar) fungal pellets concentration in $T$. versicolor inoculated continuous bioreactor (C-I). Vertical dashed lines mark changes in the $\mathrm{C} / \mathrm{N}$ ratio of the added nutrients and arrows mark renovation points of $1 / 3$ of the old pellets by fresh biomass

effluents can be in between those detected in urban and hospital wastewater effluents and, thus, some treatment at source point might be interesting to implement.

\section{Removal of PhACs and toxicity in the fungal treatment and importance of the addition of external nutrients}

T. versicolor has been reported to be able to degrade a wide range of xenobiotics, including many PhACs (Cruz-Morató et al. 2013b). Therefore, it was inoculated in air-pulsed fluidized bioreactors with the aim of achieving the degradation of PhACs present in the VHW. However, the degradation of PhACs needs other carbon sources, irrespective of whether their degradation is cometabolic or not, due to their low concentration. Moreover, previous studies reported that $\mathrm{C}$ and $\mathrm{N}$ already present in an urban wastewater were not enough for

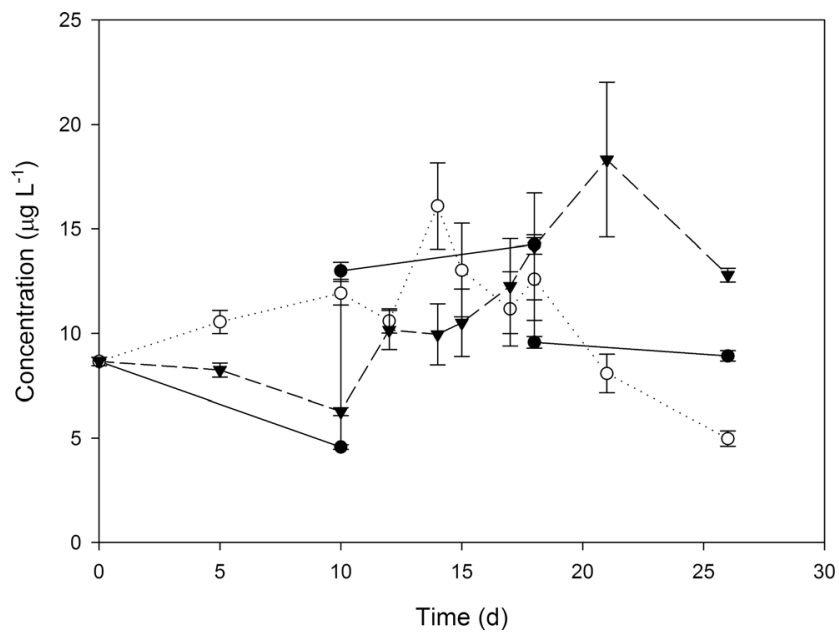

Fig. 4 Total PhACs concentration in the (black circle) inlet and the effluent of (white circle) $\mathrm{C}-\mathrm{I}$ and (inverted black triangle) $\mathrm{C}-\mathrm{NI}$ in the continuous VHW treatment the survival of $T$. versicolor under non-sterile conditions (Cruz-Morató et al. 2013a). Zhang and Geissen (2012) also pointed the need for external supply of both carbon and nitrogen in a treatment with Phanerochaete chrysosporium, another well-studied WRF. Therefore, glucose and ammonia tartrate were added in the bioreactor at the previously optimized minimum feed rate (Casas et al. 2013). However, those rates were calculated in sterile conditions, and the consumption of nutrients by the other microorganisms growing in the bioreactor as well and competing with $T$. versicolor resulted in them being insufficient for the survival of the innoculated fungus. Although, removal at B-I was $66 \%$, whereas at BNI there was no removal at all. Therefore, the inoculation with T. versicolor constituted an efficient treatment for the removal of some of the compounds, as already reported for other effluents (Cruz-Morató et al. 2014; Cruz-Morató et al. 2013a). As an example, metronidazole and diazepam, two examples of hardly biodegradable PhACs that were present in all sampled wastewaters at considerable concentration, were better removed by the fungal bioreactor at both treatments (batch and continuous).

When working in continuous mode, the increase in the glucose and ammonium tartrate feeding rate, trying to avoid fungal lysis (Fig. 3), did not help in the degradation of PhACs and survival of T. versicolor. Only after the decrease in the $\mathrm{C} / \mathrm{N}$ ratio was a stable concentration of fungus maintained, and a decrease in the total PhAC concentration was observed, highlighting the relationship between $T$. versicolor, the main fungus detected in the pellets (Fig. 5b) and the PhAC degradation. Such observation points to the fact that not only the external supply of carbon and nitrogen is important but that also the ratio between them might affect the microorganisms developing in the bioreactor and the chance for $T$. versicolor to compete with them. Further studies in that direction should be performed to optimize the nutrients needed in non-sterile treatments in order to minimize the use of chemicals and, in addition, the economic expenditures. An advisable value to start the optimization might be a $\mathrm{C} / \mathrm{N}$ ratio of around $10 \mathrm{~mol}$ $\mathrm{C} / \mathrm{mol} \mathrm{N}$ for this particular fungi and taking always into account the features of the wastewater.

Another remarkable issue regarding $\mathrm{PhAC}$ removal is the increase in the concentration of some compounds. For example, in the continuous treatment, carbamazepine was never detected in the fed wastewater, whereas it was detected in the effluent of the bioreactors. Those increases have been already reported (Badia-Fabregat et al. 2015; Cruz-Morató et al. 2013a), and this aspect has been recently deeply discussed for a similar treatment of reverse osmosis concentrate (BadiaFabregat et al. 2015). Deconjugation or other transformation reactions were postulated as the main factors for the increase of carbamazepine and ketoprofen among other compounds. Kovalova et al. (2012) also found an increase in carbamazepine concentration among other compounds after an MBR 
Fig. 5 DGGE profiles of PCR amplified a bacterial $16 \mathrm{~S}$ rRNA fragment and $\mathbf{b}$ fungal ITS fragment. Samples are from the non-sterile continuous bioreactor. In correspond to VHW feed to the reactors, $I$ to bioreactor inoculated with $T$. versicolor, NI to noninoculated reactor, and $T V$ to T. versicolor pure culture samples. Numbers of the columns correspond to the time of sampling

\section{A) BACTERIA}

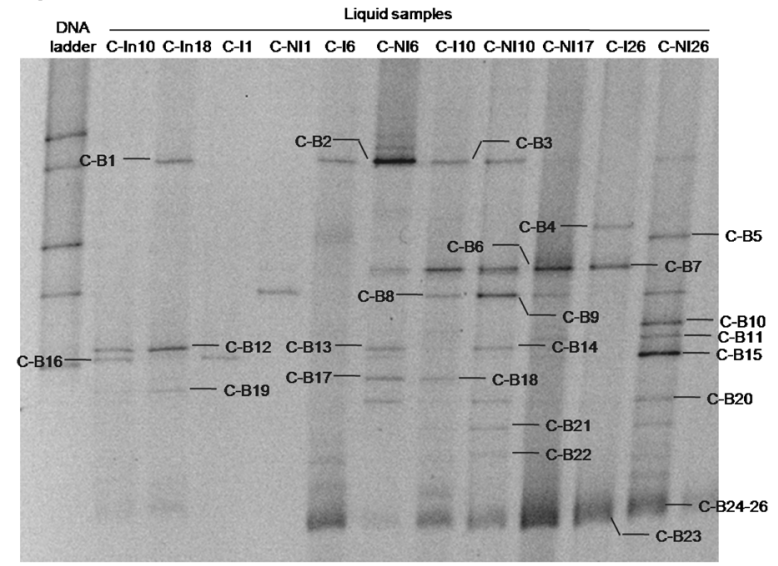

B) FUNGI

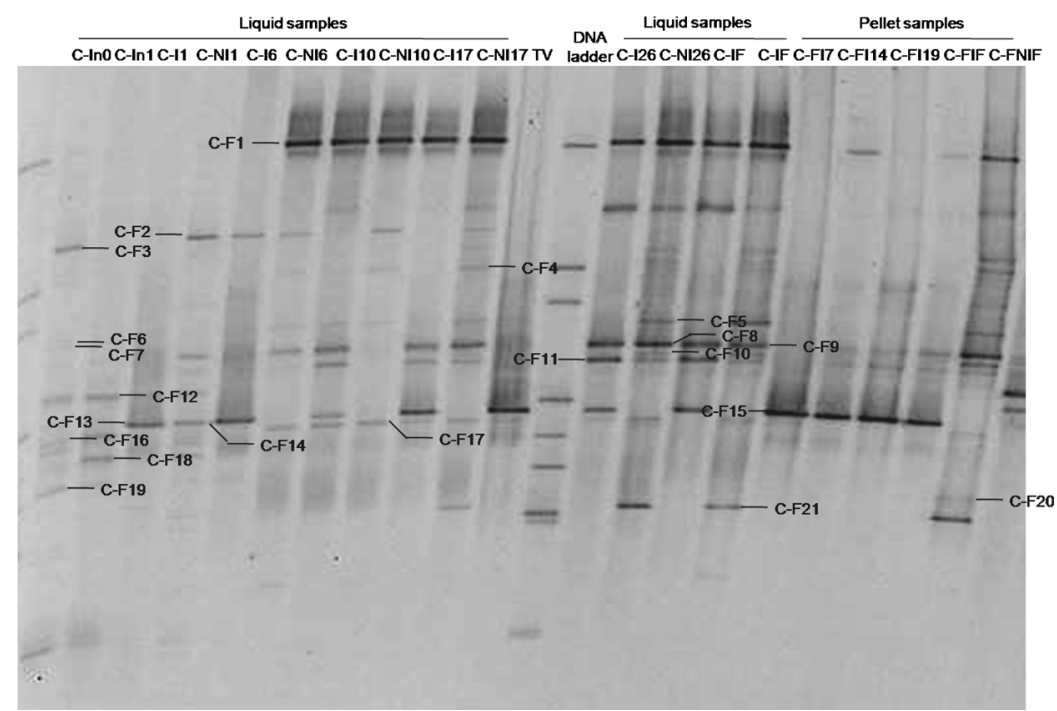

treatment of hospital wastewater due to the combined effect of deconjugation and low biodegradation. In the present study, taking into account that those increases also occurred in the non-inoculated controls, other factors beyond $T$. versicolor, such as transformation by means of bacteria or other fungi might be responsible for it. It would be very interesting to try to include conjugated compounds in the chemical analysis in order to be able to monitor all kind of treatments more accurately.

In an attempt to cover the degradation or transformation of those toxic compounds not included in the chemical analysis, a general test for acute toxicity (Microtox) was performed. VHW presented toxicity values between 1 and 20 TU, already below local legislation limits (Generalitat de Catalunya 2003). After the fungal treatments, the effluents had no toxicity at all, which means that $T$. versicolor was able to degrade those toxic micropollutants present in the wastewater, and no toxic metabolites were produced or, at least, not at significant concentrations.

\section{Role of $T$. versicolor and the competing microorganisms in the degradation of PhACs}

According to the DGGE results, the inoculated T. versicolor was active during the first 7 days in the B-I reactor. However, between days 7 and 15, it lost its predominance among fungi. On the other hand, total $\mathrm{PhAC}$ removal during the first period was $26 \%$, whereas in the second period, it reached up to $66 \%$. These results might point out that not only $T$. versicolor was the responsible for the removal of some PhACs but that some synergies were also taking place between different organisms. However, inoculation with the fungus might be crucial to achieve those synergies because in the B-NI reactor, there was no removal at all of total PhACs. In the continuous reactors, the pattern seems to be the same: if there has not been active $T$. versicolor in the bioreactor, no PhAC removal is observed. That is, in the $\mathrm{C}$-NI reactor, there is no significant $\mathrm{PhAC}$ removal nor in the $\mathrm{C}$-I reactor during the first 15 days, when $T$. versicolor pellets were lysing (Fig. 3) due to the lack 
of appropriate nutrients. It was not until the change in the $\mathrm{C} / \mathrm{N}$ ratio of the nutrients, favoring the survival of $T$. versicolor, that the degradation of PhACs seemed to differ from the noninoculated control. The detection of DGGE bands corresponding to $T$. versicolor even when deterioration of the system was observed (samples taken on days 6 and 10) might be due to the partial biomass renovations (in contrast to the non-fungal renovations in batch treatment) and that analysis was based on genomic DNA template instead of more responsive RNA (Rajala et al. 2011).

Taking into account that PhAC degradation in the fungal batch treatment seems to be performed by other microorganisms apart from $T$. versicolor, especially after day 7, PCRDGGE analyses of bacteria and fungus were performed. The presence of $T$. versicolor seems to inhibit the growth of other fungi, especially other basidiomycetes. However, the conditions in B-I reactor seemed to favor other fungi, such as Trichoderma spp., some strains of which were previously reported to inhibit T. versicolor (Bruce and Highley 1991). Nevertheless, in the continuous treatment, Trichoderma spp. were not significantly found at any VHW bioreactor, pointing to some differences between batch and continuous operation regarding the conditions for microbial community development. Contrary to the previous work pointing toward the dominance of T. versicolor over Fusarium oxysporum (RuizDueñas and Martínez 1996), in the present study, related fungi were detected in presence of $T$. versicolor. This could imply that depending on the media conditions and other microorganisms coming along in the waste water, dominant species can and will vary case-by-case.

It can be noted that fungi growing in all the bioreactors were mainly Ascomycetes, unlike in the B-NI treatment where Basidiomycetes were predominant. Almost all genera of fungi detected in both I and NI bioreactors are reported to degrade organic pollutants. For example, Fusarium and Trichoderma can degrade PAHs (Verdin et al. 2005) and Trichosporon can degrade dyes (Saratale et al. 2009). Fusarium is a ubiquitous plant pathogen fungus and was found, for example, in olivemill wastewater lagoons (Millán et al. 2000). Rhinochladiella was also found there, but its growth was limited; however, in another study, some signs of organic micropollutant transformation were provided (Fujii and Kikuchi 2005). Therefore, taking into account that $T$. versicolor was overtaken by other fungi and/or bacteria between days 7 and 15 at B-I reactor, further degradation of PhACs might be due to the activity of fungi belonging to the genera Fusarium, Trichoderma, and/or Rhinocladiella. In fact, Lu et al. (2009) reported a biofilm inoculated with a microbial consortium with decolorizing strains Fusarium oxysporum and Candida tropicalis among others that after 4 months in operation, the main fungi turned out to be Candida and a non-decolorizing species of Trichoderma. Candida spp. were present from days 6-10 onward in the continuous treatments. This is in accordance with the previous observations, as it was found to be one of the main genera at urban WWTP, together with Rhodotorula spp., Trichosporon spp., and other five unidentified genera (Yang et al. 2011).

Regarding bacteria, B-I profile at the end of the treatment was similar to the B-NI. The reason might be that there was almost no T. versicolor at that point, and bacteria that might be inhibited by $T$. versicolor could proliferate in the B-I bioreactor as well. Those bacteria probably belonged to the genera of Enterobacteriales and Rhodospirillales (bands of B-I 15d were not sequenced, assignment only by position). In the sample on day 7, although there are some bands that could not be identified, Enterobacteriales seem to be present in fewer amounts than in the absence of T. versicolor (B-I 15d and BNI). That could imply that the presence of $T$. versicolor might help in the elimination of pathogens belonging to the genera of Enterobacteriales. However, there is no other reports supporting this hypothesis, and more studies should be performed in that respect. Moreover, Enterobacteria spp. were present at each continous bioreactor, independently if it was inoculated by $T$. versicolor or not. Burkholderia spp. were also present at both continuous bioreactors and also in the batch bioreactor. Results are consistent because Burkholderia belong to $\beta$-proteobacteria, which are the major populations in environmental samples and also aerobic MBRs (Ayache et al. 2013).

No specific bacteria can be totally related with the dead of T.versicolor around day 6 of C-I because the majority of the bacteria detected at that moment were also present during all the treatment, also when $T$. versicolor recovered. The single band only present at days 6 and 10 was assigned to an unclassified proteobacteria (band C-B2, Fig. 5a)

Regarding the possible involvement of bacteria in the degradation of PhACs, as band pattern is the same at B-I 15d and B-NI $15 \mathrm{~d}$, the possible role of bacteria in the fungal reactor might be the further degradation of fungal metabolites (Mikesková et al. 2012). In the work of Lu et al. (2009), the main bacteria found after 4 months of operation of a biofilm inoculated with a mixed consortium of fungi and bacteria were $\alpha$-proteobacteria (Rhizobiales and Rhodobacterales). However, in general, there is little data in the literature regarding microbial interactions between T. versicolor (or WRF in general) and other microorganisms and, as stated before, with contradictory results. Moreover, no relationship between certain detected microorganisms and degraded PhACs could be established. Even regarding T. versicolor, although the overall concentration decreased, the degradation percentages of each compound can vary depending on the culture conditions, the wastewater, or the initial concentration, among other factors.

In the continuous bioreactors, higher diversity was generally found at the samples of the last days of the treatment, probably due to the much higher HRT than conventional growht rates, which allows proliferation of many types of 
microorganisms. However, no clear DGGE pattern change was observed between before and after the $\mathrm{C} / \mathrm{N}$ ratio change in the added nutrients. Therefore, as DGGE analysis are only qualitative, improvement in the $T$. versicolor survival might be due to quantitative differences between $T$. versicolor and the other microorganisms. Thus, although this work shows some preliminary results about microbial community development in wastewater treatments inoculated with white-rot fungi, more work should be done regarding multiple interactions and activities between fungi and bacteria in fungal treatments and their relationship with xenobiotics degradation. Moreover, it should also be taken into account that microbial community can be highly case-dependent, as shown in here. Thus, in the future, analysis of many experimental data might lead to a better correlation between operational factors and presence of certain microorganisms, being this work one of the first steps in that direction.

\section{Role of laccase activity in the degradation of PhACs and as indicator of $T$. versicolor activity}

Laccase has been reported to be the main linginolytic extracellular enzyme expressed by $T$. versicolor under similar culture conditions (Font et al. 2003). This does not mean that laccase, although it can participate, is the main enzyme involved in the degradation of PhACs. In fact, it was previously reported that extracellular enzymes are not crucial for achieving good degradation percentages of xenobiotics (Blánquez et al. 2004; Yang et al. 2013). Taking that into account, in the present study, extracellular laccase activity was analyzed and studied as a valid indicator for the $T$. versicolor activity. In the batch treatment, a positive correlation between laccase activity and $T$. versicolor survival (as shown by DGGE results) can be found. On the other hand, absence of laccase activity does not seem to affect $\mathrm{PhAC}$ degradation as there was still a significant degradation rate between days 7 and 15. Therefore, degradation could be assigned to other enzymes such as cytochrome P450 (Marco-Urrea et al. 2010) or to other microorganisms growing in the bioreactor. Taking into account the molecular biology results, it is likely to be due to the activity of other microorganisms.

On the other hand, in the fungal continuous treatment, laccase activity remained below $10 \mathrm{U} \mathrm{L}^{-1}$ after the change of the $\mathrm{C} / \mathrm{N}$ ratio in the nutrients, despite being the period when fungal pellet biomass was maintained ( $T$. versicolor was still present at both pellets and liquid samples according to DGGE analysis). It confirms, in this case, the decoupling between fungal degradation and presence of extracellular enzymes (Blánquez et al. 2008). Extracellular enzymes can be produced but degraded or inactivated by products from other microorganisms (Yang et al. 2013). In conclusion, extracellular laccase might not be a good indicator of $T$. versicolor activity, and it does not seem to be important for the degradation of PhACs either (at least in our continuous operating conditions).

\section{Strategies for fungal survival and future perspectives}

According to DGGE results of batch treatment and previous experiments (Blánquez et al. 2006), biomass was partly renewed every 2-5 days in the continuous treatment, depending on visual evolution, which results in a CRT between 6 and 15 days. This CRT should be optimized in the future at the same time as the amount of nutrients and its $\mathrm{C} / \mathrm{N}$ ratio. The amount of external nutrients to keep $T$. versicolor alive and active over the rest of microorganisms and to limit the renovation of biomass should be found. However, addition of nutrients cannot be in excess for both the higher costs (even if using waste subproducts) and the increase in the COD of the effluent that an accumulation of metabolic products in the media involves, as happened in the B-NI reactor (Fig. S1B and S2B).

On the other hand, there is a lack of studies about bacterial and fungal interactions in fungal treatments for the degradation of xenobiotic compounds. In the present work, microbial community analysis showed that after 15 days of batch treatment, T. versicolor lost its predominance. However, other fungi, such as Fusarium and Trichoderma, which could also degrade PhACs, were detected in the inoculated reactor but not in the control one. Strategies inoculating with some fungal consortium, in a similar way to what Lu et al. (2009) did, might be a good alternative and should be studied in depth.

Therefore, further optimization on nutrient requirements under non-sterile conditions and comprehensive studies on the interactions between fungi and bacteria are needed, although promising results regarding $\mathrm{PhAC}$ degradation in real wastewaters and non-sterile conditions arise from the present work.

Acknowledgments Authors want to acknowledge the UAB veterinary hospital staff for their kind permission and help for the samplings. This work has been funded by the Spanish Ministry of Economy and Competitiveness and FEDER (projects CTM2013-48545-C2 and AIB2010PT00169) and supported by the Generalitat de Catalunya (Consolidated Research Groups 2014-SGR-476 and 2014-SGR-291). The Department of Chemical Engineering of the Universitat Autònoma de Barcelona (UAB) is a member of the Xarxa de Referència en Biotecnologia de la Generalitat de Catalunya. M. Badia-Fabregat and D. Lucas acknowledge the predoctoral grants from $\mathrm{UAB}$ and from the Spanish Ministry of Education, Culture and Sports (AP-2010-4926), respectively. The authors also thank the Portuguese Foundation for Science and Technology (FCT) Strategic Project PEst-OE/EQB/LA0023/2013, Project FCOMP-010124-FEDER-027462 co-funded by Operational Competitiveness Programme, FEDER, and Project "BioEnv-Biotechnology and Bioengineering for a sustainable world," REF. NORTE-07-0124-FEDER000048, co-funded by Programa Operacional Regional do Norte (ON.2 - O Novo Norte), QREN, FEDER. 
Compliance with ethical standards All authors of the article declare that they have no conflict of interest. This article does not contain any studies with human participants or animals performed by any of the authors.

\section{References}

APHA-AWWA-WEF (1995) Standard methods for the examination of water and wastewater, 19th edn. American Public Association/ AmericaWaterWorks Association/Water Environment Federation, Washington

Asgher M, Bhatti HN, Ashraf M, Legge RL (2008) Recent developments in biodegradation of industrial pollutants by white rot fungi and their enzyme system. Biodegradation 19:771-783. doi:10.1007/s10532008-9185-3

Ayache C, Manes C, Pidou M, Croué JP, Gernjak W (2013) Microbial community analysis of fouled reverse osmosis membranes used in water recycling. Water Res 47:3291-3299. doi:10.1016/j.watres. 2013.03.006

Badia-Fabregat M, Lucas D, Gros M, Rodríguez-Mozaz S, Barceló D, Caminal G, Vicent T (2015) Identification of some factors affecting pharmaceutical active compounds (PhACs) removal in real wastewater. Case study of fungal treatment of reverse osmosis concentrate. J Hazard Mater 283:663-671. doi:10.1016/j.jhazmat.2014.10. 007

Blánquez P, Casas N, Font X, Gabarrell X, Sarrà M, Caminal G, Vicent T (2004) Mechanism of textile metal dye biotransformation by Trametes versicolor. Water Res 38:2166-2172. doi:10.1016/j. watres.2004.01.019

Blánquez P, Sarrà M, Vicent MT (2006) Study of the cellular retention time and the partial biomass renovation in a fungal decolourisation continuous process. Water Res 40:1650-1656. doi:10.1016/j.watres. 2006.02.010

Blánquez $\mathrm{P}$, Sarrà M, Vicent $\mathrm{T}$ (2008) Development of a continuous process to adapt the textile wastewater treatment by fungi to industrial conditions. Process Biochem 43:1-7. doi:10.1016/j.procbio. 2007.10.002

Bruce A, Highley TL (1991) Control of growth of wood decay Basidiomycetes by Trichoderma spp. and other potentially antagonistic fungi. For Prod J 41:63-67

Casas N, Blánquez P, Vicent T, Sarrà M (2013) Laccase production by Trametes versicolor under limited-growth conditions using dyes as inducers. Environ Technol 34:113-119. doi:10.1080/09593330. 2012.683820

Cruz-Morató C, Ferrando-Climent L, Rodriguez-Mozaz S, Barceló D, Marco-Urrea E, Vicent T, Sarrà M (2013a) Degradation of pharmaceuticals in non-sterile urban wastewater by Trametes versicolor in a fluidized bed bioreactor. Water Res 47:5200-5210. doi:10.1016/j. watres.2013.06.007

Cruz-Morató C, Rodríguez-Rodríguez CE, Marco-Urrea E, Sarrà M, Caminal G, Vicent T, Jelic A, García-Galán MJ, Pérez S, DíazCruz MS, Petrovic M, Barceló D (2013b) Biodegradation of Pharmaceuticals by Fungi and Metabolites Identification. In: Vicent T, Caminal G, Eljarrat E, Barceló D (eds) Emerg. Org. Contam. Sludges. Springer, pp 165-213

Cruz-Morató C, Lucas D, Llorca M, Rodriguez-Mozaz S, Gorga M, Petrovic M, Barceló D, Vicent T, Sarrà M, Marco-Urrea E (2014) Hospital wastewater treatment by fungal bioreactor: removal efficiency for pharmaceuticals and endocrine disruptor compounds. Sci Total Environ 493:365-376. doi:10.1016/j.scitotenv.2014.05.117

EPA (2000) Assigning values to non-detected/non-quantified pesticide residues in human health food exposure assessments. Washington
Font X, Caminal G, Gabarrell X, Romero S, Vicent MT (2003) Black liquor detoxification by laccase of Trametes versicolor pellets. J Chem Technol Biotechnol 78:548-554. doi:10.1002/jctb.834

Fujii K, Kikuchi S (2005) Degradation of benzophenone, a potential xenoestrogen, by a yeast isolated from the activated sludge of a sewage treatment plant in Hokkaido. World J Microbiol Biotechnol 21:1311-1315. doi:10.1007/s11274-005-2704-Z

Gardes M, Bruns TD (1993) ITS primers with enhanced specificity for Basidiomycetes - application to the identification of mycorrhizae and rusts. Mol Ecol 2:113-118

Generalitat de Catalunya (2003) DECRET 130/2003, de 13 de maig, pel qual s'aprova el Reglament dels serveis públics de sanejament. DOGC 11143-11158

Gros M, Rodríguez-Mozaz S, Barceló D (2012) Fast and comprehensive multi-residue analysis of a broad range of human and veterinary pharmaceuticals and some of their metabolites in surface and treated waters by ultra-high-performance liquid chromatography coupled to quadrupole-linear ion trap tandem. J Chromatogr A 1248:104-121. doi:10.1016/j.chroma.2012.05.084

Hall TA (1999) BioEdit: a user-friendly biological sequence alignment editor and analysis program for Windows 95/98/NT. Nucleic Acids Symp Ser 41:95-98

Harms H, Schlosser D, Wick LY (2011) Untapped potential: exploiting fungi in bioremediation of hazardous chemicals. Nat Rev Microbiol 9:177-192. doi:10.1038/nrmicro2519

Joss A, Zabczynski S, Göbel A, Hoffmann B, Löffler D, Mcardell CS, Ternes TA, Thomsen A, Siegrist H (2006) Biological degradation of pharmaceuticals in municipal wastewater treatment: proposing a classification scheme. Water Res 40:1686-1696. doi:10.1016/j. watres.2006.02.014

Jurado A, Vàzquez-Suñé E, Carrera J, López de Alda M, Pujades E, Barceló D (2012) Emerging organic contaminants in groundwater in Spain: a review of sources, recent occurrence and fate in a European context. Sci Total Environ 440:82-94. doi:10.1016/j. scitotenv.2012.08.029

Kaal EEJ, de Jong E, Field JA (1993) Stimulation of ligninolytic peroxidase activity by nitrogen nutrients in the white rot fungus Bjerkandera sp. Strain BOS55. Appl Environ Microbiol 59:40314036

Kovalova L, Siegrist H, Singer H, Wittmer A, McArdell CS (2012) Hospital wastewater treatment by membrane bioreactor: performance and efficiency for organic micropollutant elimination. Environ Sci Technol 46:1536-1545. doi:10.1021/es203495d

Libra JA, Borchert M, Banit S (2003) Competition strategies for the decolorization of a textile-reactive dye with the white-rot fungi Trametes versicolor under non-sterile conditions. Biotechnol Bioeng 82:736-744. doi:10.1002/bit.10623

Lu Z, Sun X, Yang Q, Li H, Li C (2009) Persistence and functions of a decolorizing fungal consortium in a non-sterile biofilm reactor. Biochem Eng J 46:73-78. doi:10.1016/j.bej.2009.04.017

Marco-Urrea E, Pérez-Trujillo M, Blánquez P, Vicent T, Caminal G (2010) Biodegradation of the analgesic naproxen by Trametes versicolor and identification of intermediates using HPLC-DADMS and NMR. Bioresour Technol 101:2159-2166. doi:10.1016/j. biortech.2009.11.019

Mikesková H, Novotný C, Svobodová K (2012) Interspecific interactions in mixed microbial cultures in a biodegradation perspective. Appl Microbiol Biotechnol 95:861-870. doi:10.1007/s00253-012-42346

Millán B, Lucas R, Robles A, García T, Alvarez de Cienfuegos G, Gálvez A (2000) A study on the microbiota from olive-mill wastewater (OMW) disposal lagoons, with emphasis on filamentous fungi and their biodegradative potential. Microbiol Res 155:143-147. doi:10. 1016/S0944-5013(00)80027-0

Nguyen LN, Hai FI, Yang S, Kang J, Leusch FDL, Roddick F, Price WE, Nghiem LD (2013) Removal of trace organic contaminants by an 
MBR comprising a mixed culture of bacteria and white-rot fungi. Bioresour Technol 148:234-241. doi:10.1016/j.biortech.2013.08. 142

Nübel U, Engelen B, Felske A, Snaidr J, Wieshuber A, Amann RI, Ludwig W, Backhaus H (1996) Sequence heterogeneities of genes encoding 16S rRNAs in Paenibacillus polymyxa detected by temperature gradient gel electrophoresis. J Bacteriol 178:5636-5643

Rajala T, Peltoniemi M, Hantula J, Mäkipää R, Pennanen T (2011) RNA reveals a succession of active fungi during the decay of Norway spruce logs. Fungal Ecol 4:437-448. doi:10.1016/j.funeco.2011. 05.005

Rodríguez-Rodríguez CE, Jelic A, Pereira MA, Sousa DZ, Petrovic M, Alves MM, Barcelo D, Caminal G, Vicent T (2012) Bioaugmentation of sewage sludge with Trametes versicolor in solid-phase biopiles produces degradation of pharmaceuticals and affects microbial communities. Environ Sci Technol 46:1201212020

Ruiz-Dueñas FJ, Martínez MJ (1996) Enzymatic activities of Trametes versicolor and Pleurotus eryngii implicated in biocontrol of Fusarium oxysporum $f$. sp. lycopersici. Curr Microbiol 32:151155. doi:10.1007/s002849900027

Santos LHMLM, Gros M, Rodriguez-Mozaz S, Delerue-Matos C, Pena A, Barceló D, Montenegro MCBSM (2013) Contribution of hospital effluents to the load of pharmaceuticals in urban wastewaters: identification of ecologically relevant pharmaceuticals. Sci Total Environ 461-462:302-316. doi:10.1016/j.scitotenv.2013.04.077

Saratale RG, Saratale GD, Chang JS, Govindwar SP (2009) Decolorization and biodegradation of textile dye navy blue HER by Trichosporon beigelii NCIM-3326. J Hazard Mater 166:14211428. doi:10.1016/j.jhazmat.2008.12.068

Verdin A, Lounès-Hadj Sahraoui A, Newsam R, Robinson G, Durand R (2005) Polycyclic aromatic hydrocarbons storage by Fusarium solani in intracellular lipid vesicles. Environ Pollut 133:283-291. doi:10.1016/j.envpol.2004.05.040

Verlicchi P, Galletti A, Petrovic M, Barceló D (2010) Hospital effluents as a source of emerging pollutants: an overview of micropollutants and sustainable treatment options. J Hydrol 389:416-428. doi:10.1016/j. jhydrol.2010.06.005

Verlicchi P, Al Aukidy M, Zambello E (2012) Occurrence of pharmaceutical compounds in urban wastewater: removal, mass load and environmental risk after a secondary treatment-a review. Sci Total Environ 429:123-155. doi:10.1016/j.scitotenv.2012.04.028

Wariishi H, Valli K, Gold MH (1992) Manganese(II) oxidation by manganese peroxidase from the basidiomycete Phanerochaete chrysosporium. Kinetic mechanism and role of chelators. J Biol Chem 267:23688-23695

Weisburg WG, Barns SM, Pelletier DA, Lane DJ (1991) 16S ribosomal DNA amplification for phylogenetic study. J Bacteriol 173:697-703

White TJ, Bruns T, Lee S, Taylor J (1990) Amplification and direct sequencing of fungal ribosomal RNA genes for phylogenetics. In: Innins MA, Gelfand DH, Sninsky JJ, White TJ (eds) PCR Protoc. Academic, San Diego, p 315

Yang Q, Angly FE, Wang Z, Zhang H (2011) Wastewater treatment systems harbor specific and diverse yeast communities. Biochem Eng J 58-59:168-176. doi:10.1016/j.bej.2011.09.012

Yang S, Hai FI, Nghiem LD, Nguyen LN, Roddick F, Price WE (2013) Removal of bisphenol A and diclofenac by a novel fungal membrane bioreactor operated under non-sterile conditions. Int Biodeterior Biodegradation 85:483-490. doi:10.1016/j.ibiod.2013. 03.012

Zhang Y, Geissen SU (2012) Elimination of carbamazepine in a nonsterile fungal bioreactor. Bioresour Technol 112:221-227. doi:10. 1016/j.biortech.2012.02.073 